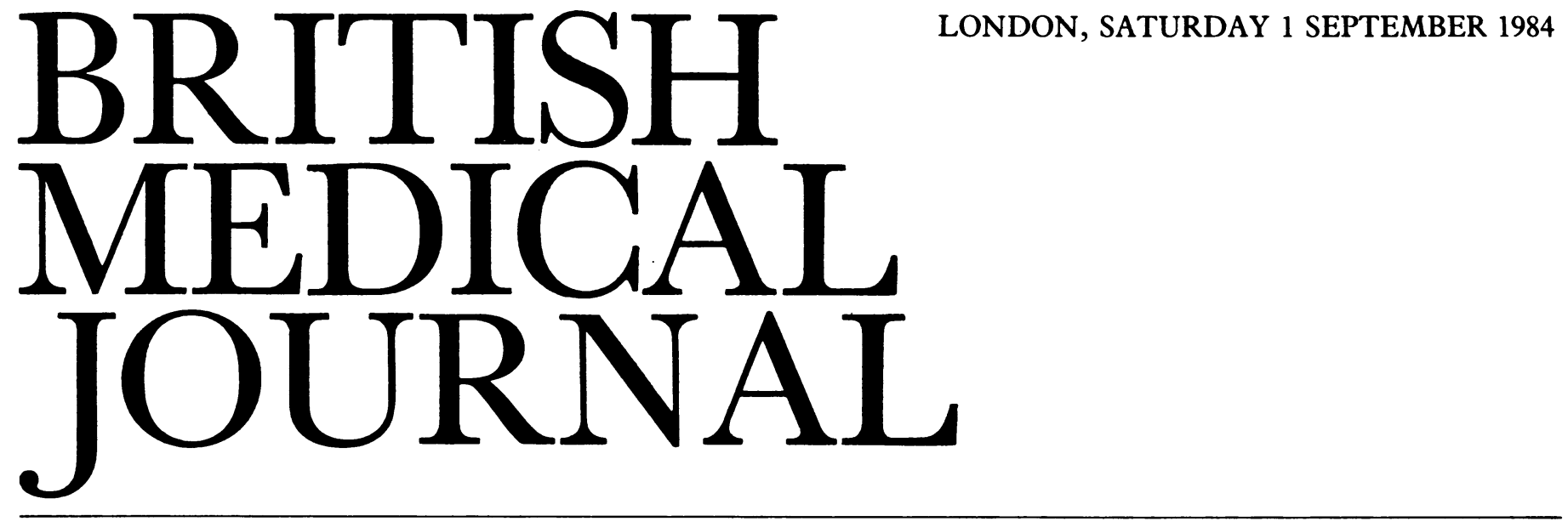

\title{
End of static decade for coronary disease?
}

Mortality from coronary heart disease has been static in Britain since 1974, when the Department of Health published its first report on diet and coronary heart disease. ${ }^{1}$ Though it took three years and 10 drafts to produce, that report was conservative and confusing. It was received with some disappointment, and in 1975 the Royal College of Physicians and the British Cardiac Society set up their own joint working party to review all factors in the prevention of coronary heart disease. ${ }^{23}$ Nutrition and diet were prominent in its recommendations about plasma lipids, obesity, and diabetes. ${ }^{4}$

The DHSS sent the joint report to all doctors in Britain. It was welcomed by the medical journals ${ }^{56}$ and, for the first time in Britain, newspaper writers took up the topic of diet and coronary heart disease enthusiastically with the inevitable oversimplifications (like "Eating animal fats may be dangerous to your health"). The butter industry reacted with the Butter Information Council, and Sir John McMichael started a correspondence opposing the dietary fat hypothesis. ${ }^{7}$

Meanwhile, the Department of Health was having second thoughts. Its report had advised against any increase in polyunsaturated fats, but the joint Royal College/Cardiac Society working party had advocated partial substitution of saturated fats by polyunsaturated. The "relatively minor difference which has tended to be magnified out of proportion" was repeatedly emphasised by the Department, and doctors sensed a battle between the experts. ${ }^{8-11}$ Thus by last year one British commentator observed "almost nothing has been done here compared to the USA. . . . Common Market policies [about dietary fat] look even sillier than most of us dared to think. . . . All the evidence is that, in comparison with ordinary Americans our people . . . are still ignorant of the main risk factors for coronary disease." Last year the National Advisory Committee on Nutrition Education wrote a compromise between the 1974 Department and Royal College of Physicians/British Cardiac Society reports. ${ }^{13}$ For all the newspaper excitement ${ }^{14}{ }^{15}$ the National Advisory Committee on Nutrition Education report took a John the Baptist position on dietary fats and coronary heart disease: "a subcommittee of the Committee on Medical Aspects of Food Policy is at present reconsidering the question of diet in relation to cardiovascular disease. The proposals set out in this document may therefore have to be revised once the new report becomes available."
The new Department of Health report Diet and Cardiovascular Disease, published last month, was prepared by a panel of the Committee on Medical Aspects of Food Policy led by Professor Philip Randle of the clinical biochemistry department, Oxford University - a neutral chairman whose publications up to now have been on other topics. ${ }^{16}$ The other nine members all have much experience in research related to diet and coronary heart disease and between them cover a range of primary disciplines and opinions. The report makes recommendations for the general public, for doctors, for the food industry, and to the government; these are summarised in this article and at p 543.

The panel advises the general public to eat less total fat and less saturated fat. For the first time the DHSS expresses this in numerical terms: total fat should be reduced from the present $41 \%$ of food energy (excluding alcohol) to $35 \%$, and saturated fat (at present over 18\% of food energy) should be $15 \%$ of energy. But this target average for saturated fatty acids should include trans fatty acids, which are metabolised similarly to saturated fatty acids. The major trans fatty acid in the diet is elaidic, trans 18:1, the steroisomer of oleic acid. The amount of trans fatty acids in the British diet has been estimated as $4 \%$ of energy, so that the panel is recommending a reduction of saturated fats per se to $11 \%$ of energy. ${ }^{17}$ This recommendation does not apply to young children or anyone already eating a low fat diet. On the other hand, people at increased risk of coronary heart disease because of a strong family history or hypercholesterolaemia or diabetes are advised to take no more than $30 \%$ of food energy as total fat and $10 \%$ of food energy as saturated fat. For diabetes this means farewell to the older, low carbohydrate diets.

The Committee on Medical Aspects of Food Policy panel makes no specific recommendations in its summary for change in consumption of polyunsaturated or monosaturated fats. But to facilitate reduction of saturated fats it says that the polyunsaturated to saturated ratio may be increased to approximately 0.45 (the present British average is said in one part of the report to be 0.23 , in another to be $0 \cdot 27)$. In the chapter on how to achieve the proposed dietary changes the panel gives as one alternative "likely to be more acceptable and therefore to be recommended" a smaller decrease in total fat with an increase in polyunsaturated fats by shifts in consumption from butter and lard to soft margarine and polyunsaturated cooking oils. But the scope 
for these exchanges, the panel warns, is limited by the recommended polyunsaturated to saturated ratio of 0.45 . Present British consumption of polyunsaturated fatty acids has reached $4.9 \%$ of food energy. The panel's recommendations work out to $7 \%$. For comparison the World Health Organisation report on coronary heart disease suggests up to $10 \%$ of dietary energy. ${ }^{18}$ The new report thus takes a moderate position on polyunsaturated fats, between the former Department and the joint reports. As the panel says, the polyunsaturated to saturated ratio that it recommends is common in many countries with a lower incidence of coronary heart disease and carries no obvious disadvantages, but the effects on the population of a ratio of 1 and beyond are unknown.

Advice on other dietary components follows in this order. The panel makes no specific recommendations about dietary cholesterol; it considers present intakes in Britain not excessive and likely to fall if saturated fat consumption is reduced. It recommends that intakes of "simple sugars" should not be increased-they are in fact falling-but does not mention any link with coronary heart disease. ${ }^{19}$ Excessive alcohol intake (over $80 \mathrm{~g} /$ day for men) is harmful in general and may adversely affect the cardiovascular system; the effects of low or moderate intakes have not been adequately tested. Salt intake is needlessly high in Britain: the panel says consideration should be given to ways of reducing it. It sees advantages in replacing the proposed reduction of dietary fat by eating more fibre rich bread, cereals, fruit, and vegetables. Obesity should be avoided or treated by appropriate food intake and regular exercise. The value of supplements of eicosapentaenoic acid requires more research and the panel cautions against their unsupervised use. Hardness of drinking water, emphasised in the 1974 DHSS report, gets no specific recommendations.

Britain has not shared in the declining mortality from coronary heart disease which started in the United States and is now being experienced in Australia, Belgium, Canada, Finland, New Zealand, Norway, and some other Western countries. Consequently Scotland, Northern Ireland, and England with Wales have moved up in the world league table of coronary deaths to second, third, and fifth positions respectively for men and first, second, and ninth positions for women. ${ }^{16}$ No reduction of average fat consumption has taken place in this country; from 1974 to 1982 it crept up from $40 \%$ to $41 \%$ of food energy, ${ }^{16}$ and plasma cholesterol concentrations may still be rising. ${ }^{20}$

The recommendations in the new report have been worked out carefully and objectively by a well balanced panel. They are consistent with the scientific evidence. Minor details of wording and the order of some recommendations may be criticised in the report, as can the unexplained discrepancy between fig 3.2 and table 3.1 and the statement that multiple risk factor intervention trials (mainly diet and smoking) have not shown convincing benefit. But here is a very sensible report. It should be the basis for concerted national action.

As the panel suggests, production of leaner meats should be encouraged and the government should consider how to remove from the Common Agricultural Policy those measures which conflict with prevention of coronary heart disease. All packaged foods should show their fat content and type on the label. More foods should be made available to the public with reduced saturated fat or salt or both. Research is needed into cheaper and simpler methods for measuring blood lipid values and blood pressure so that doctors may more readily assess their patients' coronary risk factors as suggested by Oliver. ${ }^{21}$ Health education in Britain has been ineffective so far in reducing coronary heart disease.

Doctors should be able to accept the conclusions of the 1984 report into the body of received medical knowledge"reduced saturated fat helps to prevent CHD" like "not smoking reduces lung diseases." If dissension and doubts in the British medical establishment about preventing coronary heart disease now diminish then journalists, dietitians, and schoolteachers can get on with their work of informing and educating people who have been confused. Food manufacturers and politicians will respond to public consensus and demand and Britain can at last expect a decline in premature deaths from coronary disease.

\section{A Stewart Truswell}

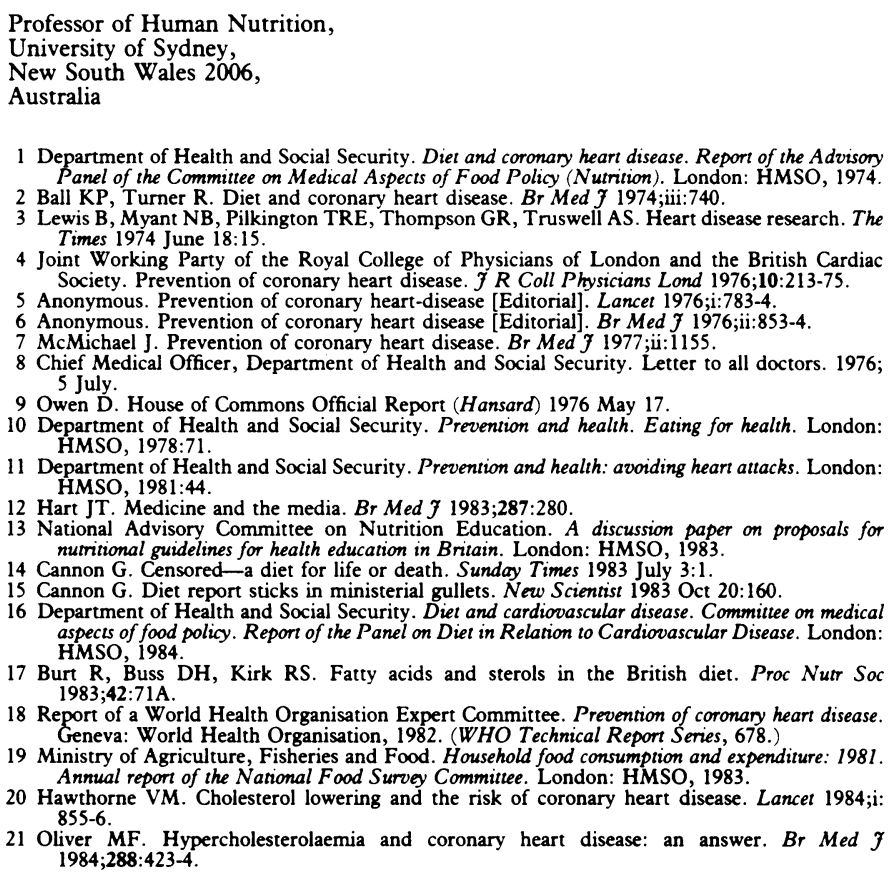

1 Department of Health and Social Security. Diet and coronary heart disease. Report of the Advisory Panel of the Committee on Medical Aspects of Food Policy (Nutrition). London: HMSO, 1974. Ball KP, Turner R. Diet and coronary heart disease. Br Med f 1974;iii:740.

3 Lewis B, Myant NB, Pilkington TRE, Thompson GR, Truswell AS. Heart disease research. The

Times 1974 June 18:15.
Joint Working Party of the Royal College of Physicians of London and the British Cardiac Society. Prevention of coronary heart disease. $\mathcal{F} R$ Coll Physicians Lond 1976;10:213-75.

5 Anonymous. Prevention of coronary heart-disease [Editorial]. Lancet 1976;i:783-4.

6 Anonymous. Prevention of coronary heart disease [Editorial]. Br Med $\mathcal{F}$ 1976;ii:853-4.

ief Medical Officer, Department of Health and Social Security. Letter to all doctors. 1976; 5 July.

10 Department ofe of Commons Official Report (Hansard) 1976 May 17. ting for health. London: HMSO, 1978:71.

1 Department of Health and Social Security. Prevention and health: avoiding heart attacks. London: HMSO, 1981:44.

12 Hart JT. Medicine and the media. Br Med f 1983;287:280.

13 National Advisory Committee on Nutrition Education. A discussion paper on proposals for nutritional guidelines for health education in Britain. London: HMSO, 1983.

4 Cannon G. Censored-a diet for life or death. Sunday Times 1983 July 3:1.

5 Cannon G. Diet report sticks in ministerial gullets. New Scientist 1983 Oct 20:160.

6 Department of Health and Social Security. Diet and cardiovascular disease. Committee on medical aspects of food policy. Report of the Panel on Diet in Relation to Cardiovascular Disease. London:

Burt R, Buss DH, Kirk RS. Fatty acids and sterols in the British diet. Proc Nutr Soc

18 Report of a World Health Organisation Expert Committee. Prevention of coronary heart disease. Geneva: World Health Organisation, 1982. (WHO Technical Report Series, 678.)

Ministry of Agriculture, Fisheries and Food. Household food consumption and expenditure: 1981.

Annual report of the National Food Survey Committee. London: HMSO, 1983.

20 Hawthorne VM. Cholesterol lowering and the risk of coronary heart disease. Lancet 1984; 855-6.

21 Oliver MF. Hypercholesterolaemia and coronary heart disease: an answer. $\mathrm{Br}$ Med $\mathrm{J}$ $1984 ; 288: 423-4$.

\section{Psittacosis}

"Sick as a parrot" has entered the vernacular, courtesy of the sporting press, and seems to be an oblique reference to psittacosis. The parrot may have been unduly maligned, as most cases of psittacosis may well be unconnected with parrots - or indeed other birds.

Chlamydia psittaci, the organism responsible for psittacosis, is an intracellular bacterium. It was originally thought to be a virus and is still listed as being synonymous with the "ornithosis virus" in the Index Medicus. Other obsolete names for the chlamydiae are bedsoniae and trachoma inclusion conjunctivitis agents. The chlamydiae have a unique two stage developmental cycle: fragile reticulate bodies are responsible for intracellular replication, and resilient elementary bodies permit transmission from one host cell to another.

The clinical presentation of psittacosis varies from a mild influenza-like illness to fulminating pneumonia complicated by lesions in other systems. Illness is most often described in adults aged $30-60$; it is only rarely reported in children. ${ }^{12}$ The incubation period is one to two weeks. The onset may be gradual with dry cough or abrupt with fever, shivering, sore throat, headache, and generalised myalgia. There may be a 